\title{
Ao sol carta é farol
}

\section{Francisca Nogueira de Azevedo}

GO M ES, Ângela deC astro (O rg.). Escrita desi, escrita da história. Rio de Janeiro: Editora FGV, 2004, 378 pp.

Ao sol carta éfarol. Esta éa metáfora usada por $M$ atildes D emétrio dos Santos para intitular seu livro sobre a correspondência entre $M$ ário de Andradee outrosmissivistas, publicado pela editora Annablume (São Paulo, 1998). 0 título sugere a importância de um olhar apropriado sobre a escrita epistolar, que nos últimos tempos tem sido objeto de interesse denúmero cada vez maior de historiadores. 0 gosto do público pelo gênero biográfico eautobiográfico cresceu muito, a partir décadadeoitenta, certamenteestimulado pelos novos aportes teórico-metodológicos experimentados pela história. Essa "nova" história exigiu a renovação das fontes, forçando 0 alargamento da documentação que vai encontrar em arquivos privados, correspondência, diários, memórias etc., filão precioso para que se pro- cesse um mergulho profundo na vida do indivíduo, o que resultou em nova reflexão do individualismo no âmbito do trabalho historiográfico. A construção de uma biografia hoje, por exemplo, sesustentaem uma metodologia explicitada onde, seu objetivo fundamental élevar à compreensão daépoca, permitindo perceber a realidade dos problemas sociais através do concreto de uma vida.

É também uma metáfora - Teatro da M emória - queservirádechave para que Ângela de Castro Gomes, a título de prólogo, introduza discussão teórico-metodológica sobre a "escrita de si", em livro organizado por ela a recém chegado as livrarias. Para a autora, "tal idéia remetediretamente ao debate já mencionado sobreo texto como representação el ou invenção desi, situando essetipo de escrita como um palco onde a encenação dos múltiplos papéis sociais e das múltiplas temporalidades do indivíduo moderno encontraria espaço privilegiado". 
N estes termos, a "escrita de s" é apropriada como estatuto de documento histórico, observando a fragmentação do indivíduo easmúltiplas transformações políticas e sociais do período em que são escritas. Como documento a "escrita de si" recupera o tempo real e permite a identificação histórica dos fatos e personagens, através da ênfase à dimensão individual desse processo. D esvendam-se então, os caminhos de uma memória que de forma voluntária ou involuntária registraa recordação de si mesma e de um outro dando sentido a representação de um tempo histórico.

$\mathrm{Na}$ realidade, 0 trabal ho com essa documentação não difere muito da crítica necessária à que o historiador submete outros tipos de fonte. $\mathrm{N} o$ entanto, determinadas características desse gênero dedocumento, especialmente no que diz respeito à "verdade" ea subjetividade histórica, tem sido, ultimamente, objeto de preocupação teórica e metodológica demuitos historiadores. Pierre Bourdieu, por exemplo, ao chamar a atenção sobre a "ilusão biográfica" oferece um caminho metodológico como condutor de uma narrativa histórica para o estudo biográfico. Para eleo "nome próprio" constitui um ponto fixo num mundo móvel, eatravés delesegaranteumaidentidadesocial eindividual em todos os campos os quais o indivíduo intervem. D essa forma, 0 "sujeito" transita em tempos eespaços diferentes, submetido a incessantes transformações, não ficando prisioneiro deum mesmo nexo, mas entendido dentro de uma dinâmica que reflete o sentido dialético da vida social.

Sem dúvida, foi este tipo de preocupação que levou Ângela de Castro G omes a organizar esta coletânea, eéa intenção de uma condução teórica-metodológica o quedife rencia este livro de outros do gênero. Fica claro o propósito de refletir e introduzir uma metodologia para o trabalho com este tipo de fonte. Assim, já no prólogo, a autora iniciaumaampla discussão sobrequestõesdeordem metodológica, quese farápresente, deformadetal hada, nos estudos que compõe a coletânea.

0 livro édividido em duas partese, em ambas, os textos obedecem auma ordem cronológica. A primejra parteécomposta por sete capítulos, cuja maioria trata da correspondência ativa e passiva deintelectuais brasileiros entre as décadas de $20 \mathrm{e}$ 40 do século passado. Há ainda, a análise de um diário de Gilberto Freyre, escrito na juventude, e um 
trabalho dos registros feitos por M onteiro Lobato sobre ele mesmo, amigos e negócios editoriais.

A segunda parte reúne nove capítulosque vão do final do século $X I X$ aos anos setenta do século $X X$, na qual encontram-se dois conjuntos de textos com abordagens teóricas bem definidas: um com questões de relativas a estudos de gênero e o outro centrado em problemas de ordem política. N esta parte, observa ainda, uma certa variedade tipológica de fontes sobre a "escrita de si". Além da correspondência e diários, encontram-setextos cujo suporte são narrativas memorialistas e entrevistas de história de vida. Como Ângela de Castro Gomes ressalta na apresentação do livro, o último estudo destaparte"não usa, por excelência, como fonte um tipo de texto queseenquadrena "escrita desi". 0 estudo analisa "bilhetinhos" enviadosaosjornais pelos censores, durante o regime militar. A organizadora justifica a inclusão do texto na coletânea pela originalidade desse tipo de documento.

"Penetrar na intimidade das cartas alheias, procurar desvendar sua subjetividadeéentrar num mundo desconhecido sempre surpreendenteeinesperado", escreve M atilde D emétrio. É essa sensação de surpre- sa, deencontro com o inesperado que setem ao ler o conjunto deartigosque integram o livro ora analisado.

Logo no primeiro texto, de autoria de $\mathrm{H}$ ebe $\mathrm{M}$ aria de $\mathrm{M}$ attos e Keila Grinberg, descobre-sea rique za do conjunto epistolar encontrado na coleção Antonio PereiraRebouças, depositada na seção de manuscritos da Biblioteca N acional. Surpreende, particularmente, os registros autobiográficos, ou "apontamentos biográficos", anotações feitas por Antônio Rebouças deepisódiosefatosque consideravaimportantesparasuabiografia. Rebouças costumava registrar a maneira como pretendia ser lembrado, eatravés deumaanálise cuida dosa das fontes as autoras chegam a condusão queAntônio Rebouças queria ser lembrado por sua "vida patriótica".

G ilberto Freyre merece destaque em dois capítulos. Um escrito pela organizadora da coletânea, e o outro, por Antônio Paulo Resende. Ângela deC astro retoma, nestetexto, a discussão teórico-metodológica que introduz o livro, só que aqui a autora faz uma análise mais específica sobre o uso da correspondência como fonte histórica. As cartas entreFreyreeO liveira Lima revelam o caminho da construção da amizade entreos doise as discussões intelectuais que travam, especialmente 
em relação à questão da raça no Brasil. N os diários de G ilberto Freyre, escritos najuventude, descortina-se a inquietação de um jovem preocupado em compreender seu tempo e a si mesmo.

No quinto e no sexto capítulos M onteiro Lobato éo intelectual escoIhido por Giselle M artins Venâncio e TâniaReginadeLuca. GiselleVanâncio, "N as C artas de Lobato aViana", nos apresenta 0 editor em diálogo com seu autor eas preocupaçõesque Lobato tinha com o mundo editorial, negócios e vida intelectual. Além disso, elas permitem invadir e penetrar naintimidade dosamigos, naconversa fiada sobre saúde, velhice, amarguras e desencantos. $\mathrm{N}$ os diários do criador do Jeca Tatu, as preocupações não são muito diferentes daquelas que revela ao amigo O liveira Viana. Sua vida de empresário editorial, a Revista Brasil e osmodernistasengrossam as páginas deseus diários. M asépossível conhecer também um outro Lobato, bem diferentedaquelequeguardamosna memória por suas histórias infantis. 0 criador deD . Benta, $\mathrm{N}$ arizinho, $\mathrm{Pe}$ drinho e outros personagens inesquecíveis - que muita al egria ainda traz as crianças através do Sítio do Pica-Pau Amarelo - no final dos anos 40 era um homem triste e de- siludido. $\mathrm{H}$ avia sido preso, perdera doisfilhos efracassara como empresário. Como assinala Tânia de Luca "não foi por acaso que Lobato escoIheu o quadro deG leyre, originalmente intitulado Ilusões Perdidas para nomear sua autobiografia".

O s outros dois capítulos que encerram a primeira parte são o de Lucia M aria Paschoal Guimarães e Valde Lopes de Araújo, sobre a correspondência passiva de John C asper Branner cientista norte-americano, membro correspondente do IH G B e da Academia Brasileira de Letras. Branner esteve no Brasil em diversas missões a serviço da Comissão G eológica do Império. A análise de sua correspondência revela a rede de sociabilidadeo prestígio social eacadêmico que o cientista tinha entre osintelectuais brasileiros. 0 último texto éde Rebeca G ontijo, eatravés do qual, como voyeur participamos da intimidade e confidências entre Capistrano de Abreu ePaulo Prado. Temas como trocas defavores, saúde, doença, memórias e o cotidiano dos dois são tratados com liberdade. C apistrano, mesmo doentenão perde o humor e ironiza suas mazelas. 0 texto permiteconhecer Capristrano de Abreu em suas múltiplasfacetas: 0 alfarrabista, editor, leitor e escritor. 
$N$ a segunda partedo livro quatro capítulos tratam de questões de gênero. Ana $M$ aria $M$ auad $\mathrm{M} M$ ariana M uaze, C elso Castro e M arieta de $M$ oraes Ferreira nos introduzem através dos diáriosda Viscondessade Arcozelo, dos diários da jovem Bernardina e da correspondência de $H$ onestalda de M oraes M artins- ao mundo de três mulheres que viveram no limiar entre o século XIX e $X X$. Esses relatosabordam o cotidiano doméstico feminino, introduzindo nova reflexão sobre o papel das mulheres na construção da sociedadebrasileira, fora do governo dacasa e dos cuidados com a família. A viscondessa, M aria I sabel de Lacerda Werneck, era dona detrêsfazendas, etinha o hábito de registrar, além da circulação de pessoas que passavam pelas fazendas, os produtos e mercadorias necessárias à manutenção diária de cada uma de suas propriedades. Anotava ainda, a época da colheita do café assim como as atividades referentes aos escravos. H onestalda, também fazendeira, tornou-se uma empresária de sucesso como gestora dosnegócios da famíliaapós a morte do marido. Administrava duas fazendase chegou a fundar um banco - Banco São Francisco de Paula. Em 1836, H onestalda arrisca a entrada no mundo da política, e é eleita prefeita de São Francisco de Paula. Bernardina Constant de $M$ agalhães Serejo é filha de um dos fundadores da República, Benjamin Constant Botelho de $\mathrm{M}$ agalhães. Bernardina registra em seu diário 0 cotidiano de uma menina de seu tempo, visitas aos amigos, passeios com a irmã, mastambém aintimidade ea vida privada do pai. Seu diário tornou-se, assim, fonteindispensável para as biografias sobre Benjamim Constant. Todos os três textos são relatos daintimidadecotidianaquesurpreendem o leitor contemporâneo.

0 décimo primeiro capítulo de autoria de Lídia M . Vianna Possas apresenta um estudo sobre as de mulheres militantesesimpatizantes daAIB (Ação IntegralistaBrasileira). A partir de referências teóricas pautadasa noção de "distância" e "estranhamento" de G inzburg - idéias desenvolvidas em seu livro Olhos de M adeira (São Paulo,2001) - a autora analisa um conjunto de missivas no período de 1932 a 1938. As cartas, de acordo com a própria Lídia Vianna, "são pontuadas por uma variedade de assuntos queinterligavam, de modo surpreendente, as dimensões públicas eprivadaeviceversa, permitindo vislumbrar níveis deintimidadeconstruídoseconsentidos entre o chefe nacional e a militância". 
No grupo de textos que tem como preocupação central a política, a correspondência de $\mathrm{G}$ etúlio Vargas é objeto de análise em dois deles. Jorge Ferreira recupera as cartas de Jango a G etúlio. A correspondência ao evidenciar registros mais íntimosepessoais das relações sociais sugerindo compartilhamento de vidas, idéias, angústias, alegrias etc. conduz o pesquisador a universo de subjetividade freqüentemente emocionante. É assim nas cartas de Getúlio alango. 0 leitor podeacompanhar passo a passo o desenvolvimento e 0 estreitamento da amizade entre os missivistas, como também seguir o crescimento da trajetória políticade João G oulart. Do mesmo modo, 0 texto de $M$ aria Celina D 'Araújo desmistifica e humaniza uma das figuras míticas de nossa história republicana. G etulio Vargas revela em sua correspondênciaum homem fragilizado e solitário, demonstrando certa obsessão pela morte. Várias de suas cartas mencionam o "sacrifício da vida" em caso de derrota. A autora demonstra ainda como em muitos registros encontrados no D iário de G etúlio encontra-setambém sua visão trágica diante dos impasses políticos. N esses relatos, em muitosmomentosamemóriade um tempo histórico torna-se real.
0 décimo quarto e décimo quinto capítulos narram a história de vida de dois militantes políticos perseguidos durante a ditadura militar no Brasil. Antonio Torres M ontenegro acompanha a trajetória de dom Antônio Fragoso, bispo de Crateús denunciado como comunista esubversivo. Antonio M ontenegro através de entrevistas e textos memorialistas, recupera a memória de dom Antônio sobre os "anos de chumbo". A história da militantede esquerda Jane Vanini - que entrou na luta armada no Brasil eviveu exilada em vários países - é analisada por Regina Beatriz G uimarães $N$ eto $\mathrm{e}$ M aria do Socorro de Souza Araújo, através da correspondência enviada para a família. As cartas foram escritasdurante seu exílio no Chileentre 1972 e 1974, ano em que foi assassinada pelos soldados da ditadura militar de Pinochet. A correspondência revela um depoimento emocionante e a trágica vida de Jane.

0 último capítulo também aborda o período do regime militar no Brasil e, como foi mencionado no início destetexto, embora as fontes não pertençam ao gênero "escrita de si", a originalidade da fonte justificou sua inclusão na coletânea. "D e ordem superior... O s bilhetinhos da censura e os rostos das vozes" é de 
autoria de Beatriz Kushnir. 0 artigo abre os arquivos para revelar como os censores atuavam nos órgãos da imprensa e as estratégias usadas por intel ectuais e jornalistas para burlar a ação da censura. Sem dúvida, uma documentação que recupera, de forma muitas vezes curiosa eaté mesmo hilária parte da história recente do país.

D essas reflexões pode-se concluir que o livro organizado por Ângela de C astro G omes, Escrita de si, escrita da história, é uma obra importante, não só pela relevância dos textos que compõem a coletânea, mas principalmente pelo fato deconjugar de maneira singular re flexões deordem teórico-metodológicas com a construção sistemática deexercícios deanálise da "escrita de si", além de indicar as variadas e instigantes possibilidades abertas pelo uso da correspondência privada como fonte para a escrita da história. 